\title{
DIMENSI EKONOMI DALAM KEHIDUPAN NABI ADAM (TAFSIR SURAT THAHA AYAT 117-119 dan SURAT AL-BAQARAH AYAT 36)
}

\author{
Satia Baktiyani Wahidah ${ }^{1}$, Ahmad Saepudin ${ }^{2}$ \\ ${ }^{1}$ Prodi Ekonomi Syariah Pascasarjana UIN Sunan Gunung Djati Bandung \\ ${ }^{2}$ Prodi Perbankan Syariah STIES Indonesia Purwakarta \\ ${ }^{1}$ satia_baktiyaniw@gmail.com \\ ²ahmadsaepudin988@yahoo.com
}

\begin{abstract}
Intisari- Kisah hikmah Nabi Adam as. Sebagai manusia pertama yang diciptakan Allah swt untuk menjadi khalifah di muka bumi. Berbekal kesempurnaan akal, nalar dan kemulyaan diantara makhluk lainnya, nabi Adam berkesempatan tinggal di syurga. Sehingga konsep sejahtera bermula dengan gambaran awal di syurga. Setelah syetan menggelincirkannya dan Allah memerintahkan keluar dari syurga, maka praktik pemenuhan kebutuhan di dunia, etos kerja produktif dan konsep kesejahteraan sebagai bagian dimensi ekonomi yang terkandung dalam kisah hikmah nabi adam as.
\end{abstract}

Kata kunci - ekonomi,nabi Adam, tafsir, surat Thaha:117-119, surat al-Baqarah:36.

Abstract - The hikmah existence of Prophet Adam saw., as the first man who is created by Allah swt to be a caliph in the earth.. Allah create him as the first man with perfection of sense, and particular among other things, and live in heaven. So the concept of prosperity begins with a preliminary description in heaven. Syetan deceive him and ordered out of heaven,has appeared practice require of needs, hard work and the concept of prosperous as part of the economic dimension.

Keywords - Economic, Prophet Adam, tafsir, surah Thaha:117-119, surah al-Baqarah:36.

\section{PENDAHULUAN}

Nabi dan rasul merupakan utusan Allah yang membawa keteladanan dan hikmah dalam kehidupan agar manusia selamat dan bahagia dunia akhirat. Di dalam Al-Quran banyak dikisahkan hikmah dan keteladanan para nabi dari berbagai aspek kehidupannya. Mereka makhluk Allah yang dipilih untuk menyampaikan risalah dan memperbaiki perilaku di berbagai bidang, diantaranya bidang ekonomi, hukum, sosial, politik, dan lain sebagainya.

Nabi pertamya sekaligus manusia pertama yang diciptakan Allah SWT adalah nabi Adam. Di dalam Al-Qur'an ditemukan penjelasan asal mula penciptaan manusia yakni penciptaan dan kehidupan awal nabi Adam di syurga yang penuh nikmat dan tidak sengsara, hingga peristiwa diturunkannya nabi Adam beserta istrinya dari syurga ke bumi yang keadaannya berbeda dengan di syurga.

Kehidupan di bumi nabi Adam harus bekerja keras memenuhi kebutuhan hidupnya, seperti kebutuhan makanan, pakaian, minuman dan bertahan dalam perbedaan cuaca. Disinilah babak baru kehidupan manusia di dunia, yakni berjuang untuk mendapatkan kebutuhan primer dan bekerja keras untuk pemenuhan kebutuhan tersebut.

Di bumi tempat manusia kelelahan, dahaga, memerlukan perjuangan untuk tetap hidup dalam berbagai keadaan cuaca. Perbedaan iklim, perbedaan sumber daya alam, keterbatasan tenaga, memaksa manusia untuk tetap berjuang memenuhi kebutuhan primernya.

Al-Qur'an surat Thaha ayat 117-119 memberikan gambaran kepada kita bahwa kehidupan di syurga penuh dengan jaminan kenikmatan. Di Syurga nabi Adam tidak kelaparan, tidak telanjang, tidak merasa dahaga dan tidak ditimpa panas matahari. Dikarenakan tipu daya syetan, sehingga mereka dikeluarkan dari syurga, seperti yang dijelaskan dalam AlQuran surat Al-Baqarah ayat 36.

Di dalam makalah ini, penulis mencermati dimensi ekonomi dalam kehidupan nabi Adam dan kaitannya dengan tafsir Al-Quran surat Thaha ayat 117-119 serta Al-Baqarah ayat 36.

\section{PEMBAHASAN}

A. Sejarah Penciptaan Adam dan Dikeluarkannya Dari Syurga

Pada awal penciptaan manusia, Allah SWT hendak menjadikannya sebagai khalifah di muka bumi. Yakni suatu kaum yang akan menggantikan satu sama lain, kurun demi kurun, dan generasi demi generasi. Sebagaimana yang dijelaskan dalam Al-Qur'an Surat Al-Baqarah Ayat 30, bahwasannya Allah SWT berfirman kepada para malaikat hendak menciptakan Adam dan keturunannya sebagai khalifah di bumi yang akan membuat kerusakan dan menumpahkan darah. Sehingga saat itu para malaikat berkata mengapa Allah SWT hendak menjadikan Khalifah di bumi itu orang yang akan membuat kerusakan dan menumpahkan darah.

Sebagian ulama mengatakan, sesungguhnya malaikat mengatakan seperti itu karena Allah mengizinkan mereka untuk bertanya ihwal hal itu setelah diberitahukan kepada mereka bahwa khalifah itu terdiri atas keturunan Adam. ${ }^{1}$ Pada awalnya malaikat menyangka bahwa keturunan Adam hanya akan menumpahkan darah dan membuat kerusakan di muka bumi.Mereka tidak menduga bahwa diantara keturunan Adam ada yang akan menjadi nabi, orang shaleh dan wali. Allah berfirman pada akhir ayat ke 30 Surat Al-Baqoroh, “...Sesungguhnya Aku mengetahui apa yang tidak kamu ketahui."."
${ }^{1}$ Muhammad Nasib ar-Rifa'I yang diterjemahkan oleh Drs. Syihabuddin, Kemudahan dari Allah Ringkasan Tafsir Ibnu Katsir,(Jakarta:Gema Insani Press,1999),I,hlm 105.
2 Lajnah Pentashihan Mushaf Al-Quran Kementerian Agama RI,AlQur'an,(Bandung:Pt. Madina Raihan Makmur,2010),hlm 6 
Allah membekali Adam dengan pengetahuan tentang namanama benda seluruhnya yang tidak diketahui dan tidak diajarkan kepada malaikat. Allah memuliakan Adam diantara makhluk lainnya, bahkan mereka diminta bersujud kepada Adam.Perintah sujud tersebut sebagai ketaatan ditujukan kepada Allah dan dan sujud bagi Adam. Demikianlah, malaikat bersujud kecuali Iblis. Ibnu Jarir mengutip melalui sanad alHasan bahwasannya dia berkata "Iblis sama sekali bukan dari golongan malaikat. Iblis adalah asli bangsa jin , sebagaimana Adam dari bangsa manusia. ${ }^{3}$

Keingkaran Iblis untuk bersujud kepada manusia dikarenakan takabur dan hasud atas kemuliaan yang telah diberika Allah.Iblis berkata "Aku terbuat dari api dan orang ini dari tanah".Kedurhakaan merupakan dosa pertama iblis yang disebabkan oleh kesombongan.

Adapun malaikat, mereka patuh pada perintah Allah.Mereka menerima dan mengakui kehadiran manusia sebagai khalifah sebagaimana hadits riwayat Bukhori "Lalu mereka datang kepada Adam seraya berkata, "Engkau adalah bapak manusia, Allah telah menciptakanmu dengan tangan kekuasaan-Nya, dia membuat para malaikat bersujud kepadamu, dan dia mengajarimu nama-nama seluruh perkara."4

Selain diberi kemuliaan, Adam diberi kesempatan untuk mendiami syurga beserta istrinya (Hawa). Disana mereka mendapatkan kenikmatan untuk memakan makanan yang melimpah lagi baik sehingga tidak akan kelaparan. Mereka mendapat pakaian sehingga tidak akan telanjang. Allah memberikan petunjuk dan menasehati Adam untuk mengindari syetan karena mereka adalah musuh ia dan istrinya. Maka, janganlah syetan itu menyebabkan kalian keluar dari syurga sehingga kalian sengasara dengan berbagai kepayahan dunia yang hampir tidak dapat dihitung. ${ }^{5}$

Apapun makanan yang diinginkan boleh dinikmati. Kecuali satu pohon di syurga yang dilarang untuk didekati. Namun keduanya digelincirkan oleh syetan dari syurga disebabkan keduanya memakan buah dari pohon itu sehingga keduanya menjadi jauh dan terjerumus kedalam kesalahan dan kedurhakaan terhadap larangan Allah.Akhirnya mereka dikeluarkan dari syurga dan dari keadaan semula.

Sebagaimana firman Allah dalam Surat Al-Baqoroh ayat 36:" Lalu syetan memperdayakannya dari syurga sehingga keduanya dikeluarkan dari (segala kenikmatan) ketika keduanya disana (syurga). Dan Kami berfirman, "Turunlah kamu! Sebagian kamu menjadi musuh bagi yang lain. Dan bagi kamu ada tempat tinggal dan kesenangan di bumi sampai waktu yang di tentukan."'6

Inilah sejarah perjuangan manusia mempertahankan kehidupannya dengan berusaha memenuhi kebutuhan pokoknya di dunia. Awal mula manusia harus berjuang memenuhi kebutuhan makanan, pakaian, minuman, dan menghadapi perbedaan cuaca di dunia. Sehingga selain kebutuhan primer, manusia juga memerlukan perlindungan dan rasa aman. Disinilan awal mula perilaku dan dimensi ekonomi dalam kehidupan nabi Adam.

\footnotetext{
3 Muhammad Nasib ar-Rifa'I yang diterjemahkan oleh Drs. Syihabuddin,Op.cit,hlm 110

4 Muhammad Nasib ar-Rifa'I yang diterjemahkan oleh Drs. Syihabuddin,Op.cit,hlm 107.

${ }_{5}^{5}$ Bahrun Abu Bakar, Lc, dkk,Terjemah Tafsir Al-Maraghi,(Semarang:PT. Karya Putra Toha,1993),XVI, hlm292

${ }^{6}$ Lajnah Pentashihan Mushaf Al-Quran Kementerian Agama RI,AlQur'an,.Loc.Cit
}

B. Terjemah Surat Thaha Ayat 117-119 dan Al- Baqarah Ayat 36

Lafazh dan Terjemah Al-Quran surat Thaha ayat 117-1197

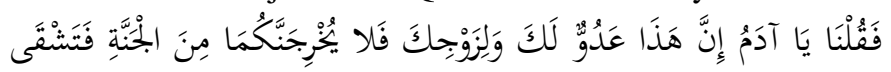

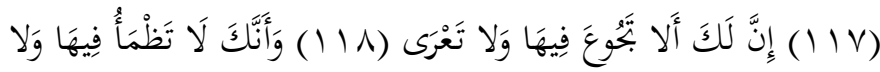<smiles>CCCCCCCC</smiles>

117) Maka berkatalah Kami: Hai Adam, sesungguhnya dia ini adalah musuhmu dan musuh bagi istrimu, maka janganlah (sampai) dia keluarkan kalian keduanya dari dalam syurga, karena engkau akan sengsara dibuatnya.

118) Sesungguhnya karunianya untuk engkau bahwa engkau tidak merasakan lapar di dalamnya dan tidak akan pula bertelanjang.

119) Dan sesungguhnya engkau tidak akan haus padanya dan tidak akan merasa kepanasan

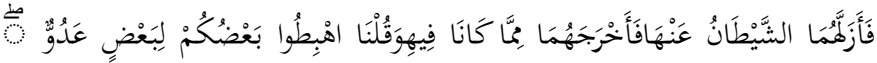

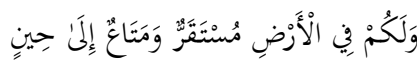

Lalu keduanya digelincirkan oleh syaithan dari surga itu dan dikeluarkan dari keadaan semula dan kami berfirman: "Turunlah kamu! Sebagian kamu menjadi musuh bagi yang lain, dan bagi kamu ada tempat kediaman di bumi, dan kesenangan hidup sampai waktu yang ditentukan. (QS. AlBaqarah: 36$)^{8}$

\section{Kosa Kata dan Korelasi Surat Thaha Ayat 117-119 dan Al- Baqarah Ayat 36 \\ Terdapat beberapa penjelasan kosa kata diantaranya: ${ }^{9}$}

فتشق yaitu merasa susah dengan berbagai kesusahan dunia yang hampir tidak bisa dihitung karena banyaknya

تظما

تضحى yaitu engkau sinar matahari mengenaimu. Berarti dia mendapat sinar matahari yang terik.

Korelasi ayat ini dengan ayat sebelumnya adalah bahwa setelah dalam ayat sebelumnya Allah mengagungkan al-Quran, dan menjelaskan hal-hal yang terkandung dalam al-Quran berupa ancaman yang tujuannya untuk melatih ketakwaan, untuk nasehat serta untuk pelajaran, kemudian selanjutnya diikuti oleh kisah Nabi Adam, untuk menunjukan bahwa ketaatan manusia kepada syaithan itu adalah perkara yang sangat klasik. Mereka melupakan perintah-perintah ilahiyyah, sebagaimana bapak mereka, Adam, melupakannya.

Di sana pun diceritakan keengganan iblis untuk bersujud kepada Adam, untuk memberi peringatan bahwa sebenarnya Iblis itu adalah musuh manusia yang telah mengeluarkan Adam dari surga. Ayat ayat tentang perintah kepada malaikat, supaya bersujud kepada Adam diceritakan di dalam Al-Quran hingga 7 kali: ${ }^{10}$

1. Surat Al-Baqarah ayat $30-38$

2. Surat Al-A'raf ayat 11-27

3. Surat Al-Hijr ayat $28-43$

4. Surat Al-Isra' ayat 61-65

\footnotetext{
7 HAMKA, Tafsir Al-Azhar Juzu XVI,(Jakarta:PT.Pustaka Panjimas, 1988), hlm 229.

8 Muhammad Nasib ar-Rifa'I yang diterjemahkan oleh Drs. Syihabuddin,Op.Cit,hlm 111

${ }^{9}$ Bahrun Abu Bakar, Lc, dkk, Op.Cit, hlm 288

${ }^{10}$ HAMKA, Op.Cit, hlm 231.
} 
5. Surat Al-Kahfi ayat 50-51

6. Surat Thaha ayat $115-123$

7. Surat Shaad ayat 71-85

Hikmahnya adalah untuk menanamkan dalam jiwa manusia nahwa sebagai keturunan Adam mereka lebih dimuliakan oleh Allah. Lantas Allah menjelaskan pahala bagi orang yang taat patuh terhadap petunjuk ilahi, dan balasan siksa bagi mereka yang berpaling, dan bahwa dia akan dikumpulkan di padang mahsyar dalam keadaan buta dari petunjuk yang dapat menyelamatkan mereka dari siksa karena ketika di dunia dia berpaling dari ayat-ayat yang jelas yang menjadi petunjuk ke jalan yang benar.

Adapun korelasi surat Thaha dengan surat al-Baqarah ayat 36 di atas adalah terkait dengan tema yang sama, yaitu tentang kisah Nabi Adam, dan status iblis sebagai musuh manusia yang menyebabkan bapak mereka, Adam, tergelincir dalam dosa.

\section{Tafsir Al-Quran Surat Thaha Ayat 117-119 dan Al- Baqarah Ayat 36}

Pada Surat Thaha ayat 117 Allah memberikan peringatan kepada Adam dan istrinya untuk senantiasa berwaspada akan musuhnya yaitu Iblis. Karena Iblis akan selalu berusaha mengeluarkan mereka berdua dari syurga, lalu mereka kepayahan karena harus mencari rezeki.Karena kehidupan di syurga menyenangkan dan sejahtera tidak ada beban penderitaan sedangkan iblis menginginkan kehidupan mereka celaka. "Sesungguhnya kamu tidak akan kelaparan di dalamnya dan tidak akan telanjang." Dalam penggalan ini kata lapar merupakan kehinaan batin dan telanjang merupakan kehinaan lahir. "Dan sesungguhnya kamu tidak akan merasa dahaga dan tidak akan ditimpa panas sinar matahari didalamnya." Kedua kata ini pun merupakan padanan: dahaga merupakan panas batiniyah dan panas matahari merupakan panas lahiriyah. ${ }^{11}$

Kendati mereka diberi kebebasan, namun kebebasan ini terbatas. Sebagaimana yang diceritakan pada Al-Quran surat Al-Baqarah ayat 35, Allah berfirman "Dan janganlah kamu mendekati pohon ini" adalah pemberitahuan dari Allah dan ujian bagi Adam.Para ulama bersilang pendapat mengenai nama pohon itu.Ada yang mengatakan ia merupakan pohon kemuliaan, ada lagi yang, mengatakan pohon gandum,ada pula yang mengatakan pohon tin, ada yang mengatakan pohon sunbulah, dan ada pula yang mengatakan pohon kurma.Yang benar adalah pohon di syurga. ${ }^{12}$

Lalu syetan menggelincirkan mereka dan mengeluarkan mereka dari keadaan bahagia yang pernah mereka rasakan. ${ }^{13}$ Syetan memberikan rayuan dengan sebuah pohon khuldi dan kerajaan yang tidak akan binasa. Sehingga Adam dan istrinya memakan buah khuldi.

"Dan Kami berfirman, 'Turunlah kamu! Sebagian kamu menjadi musuh bagi yang lain, dan bagi kamu ada tempat kediaman di bumi dan kesenangan hidup hingga waktu yang ditentukan," yakni tempat tinggal rezeki dan ajal sampai waktu yang ditenyukan, lalu terjadilah kiamat.Riwayat mengenai tempat turunnya Adam, Hawa, dan Syetan berbeda-beda. Ada pendapat yang mengatakan bahwa Adam diturunkan di India dan diturunkan pula bersamanya Hajar Aswad. Sementara Hawa diturunkan di Jedah, sedangkan Iblis diturunkan di Dastamaisan, dekat Bashrah. ${ }^{14}$

\footnotetext{
${ }^{11}$ Muhammad Nasib ar-Rifa'I yang diterjemahkan oleh Drs. Syihabuddin, Kemudahan dari Allah Ringkasan Tafsir Ibnu Katsir,(Jakarta:Gema Insan Press,1999),III,hlm 274.

12 Muhammad Nasib ar-Rifa'I yang diterjemahkan oleh Drs. Syihabuddin,Loc.Cit.
}

\section{E. Dimensi Ekonomi dalam Kehidupan Nabi Adam}

Manusia memiliki kebutuhan akan hal-hal yang dapat memberikannya kenyamanan hidup. Kebutuhan itu bisa kita lihat dan rasakan sendiri.Kebutuhan itu baik berupa kebutuhan lahir maupun batin, terutama kebutuhan mendasar dalam hidup mereka, yaitu sandang, pangan, dan papan.

Kebutuhan jasmani lahir karena adanya kerja struktur organ tubuh manusia.Kebutuhan ini memerlukan pemenuhan berupa keadaan, benda serta aktivitas tertentu. Keadaan yang diperlukan oleh tubuh manusia antara lain tidur, rehat, dan suhu udara tertentu. Benda yang diperlukan manusia antara lain, makanan, minuman, pakaian dan tempat tinggal. ${ }^{15}$

Hal-hal itu telah dijelaskan dalam ayat-ayat yang disebutkan pada bagian pertama makalah ini.Bahkan ayat tersebut mengisyaratkan pada kebutuhan dasar manusia yang mesti dipenuhi. تجو dan تعرى menuntut untuk dipenuhi dengan makanan dan pakaian, serta نظمأ نضحى dan نضع yang menunut untuk dipenuhi dengan air yang segar dan teduhan.Keempat hal itu dalam ilmu ekonomi disebut sebagai kebutuhan primer.

Adapun kebutuhan manusia yang sifatnya pelengkap memang akan selalu berkembang terus bertambah seiring dengan tingkat kesejahteraan individunya. Adanya kebutuhan ini tersirat dalam surat al-Baqarah ayat 36 di atas, yaitu pada kalimat مناع yang artinya kenikmatan-kenikmatan dunia yang memberikan kebahagian kepada manusia, yang cakupan maknanya lebih luas dari sekedar sandang, pangan, dan papan. Termasuk juga makanan enak, pakaian yang bagus, dan rumah yang mewah, dan kebutuhan-kebutuhan pelengkap lainnya.

Dalam lingkup keluarga.Pemeran utama dalam pemenuhan kebutuhan dasar dirinya dan keluarganya adalah suami.Suami sebagai pemegang tanggung jawab ekonomi keluarga. Hal itu tersirat juga dalam ayat dari surat thaha di atas. Sebagaimana dijelaskan oleh para mufassir, bahwa penisbatan kata تشقى hanya kepada Adam, tidak dengan Hawa, memiliki makna bahwa Adam lah yang harus bersusah payah memenuhi kebutuhan dirinya dan istrinya. Dialah yang berkewajiban memberikan keluarga makan ketika lapar (تجوع) , haus ketika minum (تظمأ (تعرى), pakaian untuk menutup aurat), dan teduhan untuk tempat tinggal(تضحى).

Allah menegaskan hal tersebut dalam firman-Nya,

$$
\text { وعلى المولود له رزقهن وكسوتن بالمعروف }
$$

"Dan Kewajiban bagi ayah adalah memberi mereka rezeki (makanan dan minuman) dan pakaian dengan cara yang baik" (QS. Al-Baqarah ayat 233)

Dalam ayat lain Allah berfirman:

$$
\text { اسكنواهن من حيث سكنتم من وجدكم }
$$

Tempatkanlah mereka (para istri) di tempat kalian tinggal menurut kemampuan kalian" (QS. Ath-Thalaq: 6)

Lebih luas, pemenuhan kebutahan satu masyatakat dalam satu Negara menjadi tanggung jawab pemerintah sebagai pemegang urusan dan pemangku kebijakan.Dalam arti bahwa pemerintah harus memberikan fasilitas dan akses kepada masyarakat untuk memenuhi kebutuhan hidup mereka, baik sandang, pangan, papan, dan juga pendidikan sebagai modal menuju kesejahteraan yang lebih tinggi bahwa Negara atau

13 Allamah Kamal Faqih Imani yang diterjemahkan oleh R. Hikmat Danaatmaja, S.Pd.,Tafsir Nurul Quran, (Jakarta:Al-Huda,2003),hlm 169

14 Muhammad Nasib ar-Rifa'I yang diterjemahkan oleh Drs. Syihabuddin,Op.cit,hlm 112

${ }^{15}$ Ismail Yusanto dan M. Arif Yunus,Pengantar Ekonomi Islam, (Bogor: al-Azhar Pres, 2011) Hlm.41 
pemerintah memiliki kewajiban untuk memenuhi kebutuhan masyarakat. Yaitu dengan meyediakan lapangan pekerjaan dengan cara menciptakan kondisi agar perekonomian bisa tumbuh dengan sebaik-baiknya, sehingga lapangan kerja akan selalu tercipta. Imam al-Ghazali menyatakan bahwa wajib bagi waliyyul amri memberikan sarana-sarana pekerjaan kepada para pencari kerja.Menciptakan lapangan kerja adalah kewajiban Negara dan merupakan bagian dari tanggung jawabnya terhadap pemeliharaan dan pengaturan urusan rakyat.

Kewajiban-kewajiban pemerintah itu dimaksudkan untuk mewujudkan masyarakat yang ideal.Masyarakat yang ideal adalah ketika seluruh individu anggotanya terbebas dari kemiskinan.Seluruh kebutuhan pokoknya terpenuhi dan kebutuhan pelengkap sesuai dengan kemampuan masingmasing terbuka untuk dapat diupayakan terpenuhi pula ${ }^{16}$ Itulah yang kemudian bisa kita sebut sebagai kesejahteraan masyarakat.Islam sangat mendorong untuk mewujudkan kesejahteraan masyarakat. Terdapat sejumlah argumentasi baik yang bersifat teologis normatif, maupun rasional filosofis yang menegaskan tentang betapa ajaran Islam amat peduli dalam mewujudkan kesejahteraan sosial.

Pertama dilihat dari pengertiannya, sejahtera sebagaimana dikemukakan dalam Kamus Besar Indonesia adalah aman, sentosa, damai, makmur dan selamat (terlepas) dari segala macam gangguan, kesukaran dan sebagainya. Pengertian ini sejalam dengan pengertian Islam yang berarti selamat, sentosa, aman dan damai. Dari pengertiannya ini dapat diketahui bahwa masalah kesejahteraan sosial sejalan dengan missi Islam itu sendiri. Missi inilah yang sekaligus menjadi missi kerasulan Nabi Muhammad SAW, sebagaimana dinyatakan dalam ayat yang berbunyi :

$$
\text { وَمَا أَرْسَلْنَاكَ إِلَّا رَهْمَة لِلْعَالَمِينَ) }
$$

Artinya: Dan tidalah kamu mengutus kamu, melainkan untuk (menjadi) rahmat bagi seluruh alam. (Q.S. al-anbiya' 21:107)

Kedua dilihat dari segi kandungannya, terlihat bahwa seluruh aspek ajaran Islam ternyata selalu terkait dengan masalah kesejahteraan sosial. Hubungan dengan Allah misalnyaharus dibarengi dengan hubungan dengan sesama manusia (habl min Allah wa habl min alNas). Demikian pula anjuran beriman selalu diiringi dengan ajuran melakukan amal salih yang didalamnya termasuk mewujudkan kesejahteraan sosial. Selanjutnya ajaran Islam yang pokok yakni Tukun Islam, seperti mengucapkan dua kalimah syahadat, shalat, puasa, zakat dan haji sangat berkaitan dengan kesejahteraan sosial. Orang yang mengucapkan dua kalimah syahadat adalah orang yang komitmen bahwa hidupnya hanya akna berpengan pada pentunjuk Allah dan Rasul-Nya, karena tidak mungkin orang mau menciptakan ketenangan, jika tidak ada komitmen iman dalam hati nya. Demikian pula ibadah shalat (khususnya yang dilakukan secara berjama'ah) mengandung maksud agar mau memperhatikan nasib orang lain. Ucapan salam pada urutan terakhir dalam tarnyam dan berupaya mewujudkan kedamaian. Selanjutnya dalam ibadah puasa seseoarnag diharapakan dapat merasakan lapat sebagaimana yang biasa dirasakan oleh orang lain yang berada dalam kekurangan. Kemudian dalam zakat, tampak jelas unsur kesejahteraan sosialnya lebih kuat lagi. Demikian pula dengan ibadah haji, dihapkan agar ia memiliki sikap merasa sederajat dengan manusia lainnya.
Ketiga, bahwa upaya mewujudkan kesejahteraan sosial, merupakan missi kwkhalifahan yang dilakukan oleh Nabi Adam AS.sebagian pakar, sebagaimana dikemukakan H.M. Quraish Shihab dalambukunya Wawasan Al-Quran (hal. 127), menyatakan bahwa kesejahternaan sosial yang didambakan al-Quran tercermin di Surga yang dihuni oleh Adam dan istirinya, sesaat sebelum turunnya mereka melaksanakan tugas kekhalifahan di bumi.

Seperti diketahuin, bahwa sebelum Adam dan istirinya diperintahkan turun kebumi, mereka terlebih dahulu ditempatkan di surga.Surga diharapkan menjadi arah pengabdian Adam dan Hawa, sehingga bayang-bayang surga itu diwujudkan di bumi, serta kelak dihuninya secara hakiki di akhirat. Masyarakat yang mewujudkan bayang-bayang surga itu adalah masyarakat yang berkesejahteraan. Kesejaterjaan surgawi ini dilukiskan antara lain dalam firman-Nya yang berbunyi :

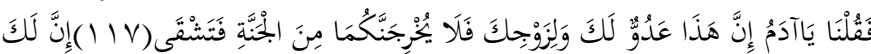

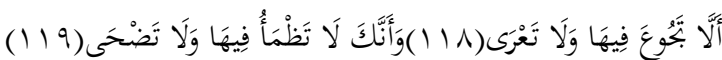

Artinya: Hai adam, sesungguhnya ini (iblis) adalah musuh bagimu dan bagi istirimu, maka sekali-kali jangan sampai ia mengeluarkan kamu berdua dari surga, yang akibatnya engankau akan bersusah payah. Sesungguhnya engakau tidaka akan kelaparan di sisni (surga), tidak pula akan telanjang, dan sesungguhnya engakau tidak akan merasakan dahaga maupun kepanasan. (Q.S. Thaha, 20:117-119).

Dari ayat ini jelas bahwa pangan, sandang, dan papan yang diistilahkan dengan tidak lapar, dahaga telanjang dan kepanasan semuanya telah terpenuhi di sana. Terpenuhinya kebutuhan ini merupakan unsur pertama dan utama kesejahteraan sosial.

Keempat, di dalam ajaran Islam terdapat pranata dan lembaga yang secara langsung berhubungan denganupaya penciptaan kesejahteraan sosial, seperti wakaf dan sebagainya. Semua bentuk pranata sosial dan berupaya mencari berbagai alternatuf untuk mewujudkan kesejahternaan sosial. Namun suatu hal yang pelu dicatat, adalah bahwa berbagai bentukpranat ini belum merata dilakukan oleh ummat Islam, dan belum pula efektif dalam mewujudkan kesejahteraan sosil. Hal ini mungkin disebabkan belum munculnya kesadaran yang merata serta pengelolaannya yang baik. Untuk itulah saat ini Pemerintah, melalui Kementerian Agama, membentuk semacam Lembaga Amil Zakat (LAZ) tingkat Nasional.Berhasilkan konsep ini dalam mewujudkan kesejahteraan sosial, amat bergantung kepada partisipasi kita.

Kelima, ajaran Islam mengenai perlunya mewujudkan kesehateraan sosial ini selain dengan cara memberikan motivasi sebagaimana tersebut di atas, juga disertai dengan semangat bekerja keras sebagai prinsip bentuk kerja positif. Ajaran Islam menyatakan bahwa kesehateraan sosial dimulai dari perjuangan mewujudkan dan menumbuh suburkan aspek-aspek akidah dan etika pada diri pribadi, karena dari diri pribadi yang seimbang akan lagri masyarakat yang seimbang. Masyarakat Islam pertama lahir dari Nabi Muhammad SAW, melalui kepribadian beliau yang sangat mengagumkan. Pribadi ini melahirkan keluarga yang seimbang seperti Khadijah, Ali bin Abi Thalib, Fatimah AzZahra, dan lain-lain. Selain itu ajaran Islam menganjurkan agar 


\section{EKSISBANK Vol. 2 No. 2 Desember 2018}

tidak memanjakan orang lain, atau kreatifitas orang lain, sehingga orang tersebut tidak dapat menolong dirinya sendiri. Bantuan keuangan baru boleh diberikan apabila seseorang ternyata tidak dapat memenuhi kebutuhannya. Ketika seseorang datang kepada Nabi SAW.mengadukan kemiskinannya, Nabi SAW tidak memberinya uang, tetapi kapak agar digunakan untuk mengambil dan mengumpulkan kayu. Dengan demikian, ajaran Islam tentang kesejahteraan sosial ini termasuk di dalamnya ajaran Islam tentang kesejahteraan sosial .

Keenam, kebutuhan akan perlindungan dan rasa aman. Frase "sebagian kamu menjadi musuh bagi yang lain" menggambarkan kehidupan itu akan penuh permusuhan, karenanya kebutuhan akan perlindungan dan rasa aman menjadi prioritas untuk dipenuhi setelahnya. ${ }^{17}$

\section{KESIMPULAN}

Dari uraian di atas, ada beberapa hal yang bisa kita ambil sebagai simpulan atau hal yang pokok, yaitu:

1. Bahwa iblis dan syaithan merupakan musuh umat manusia

2. Prilaku ekonomi dalam arti yang sangat dasar yaitu pemenuhan kebutuhan hidup sudah dilakukan sejak manusia pertama, Adam.

3. Kebutuhan primer manusia adalah sandang, pangan, dan papan.

4. Pemenuhan kebutuhan manusia menjadi tanggung jawab pemimpin sesuai dengan lingkupnya, pribadi, suami untuk keluarga, pemimpin Negara untuk masyarakat/ rakyat negaranya.

5. Bekerja keras adalah prinsip bentuk kerja positif untuk mewujudkan kesejahteraan

\section{REFERENSI}

[1] Abu Bakar, Bahrun, dkk.1993. Terjemah Tafsir Al-Maraghi XVI Semarang:PT. Karya Putra Toha

[2] Danaatmaja,R. Hikmat.2003. Tafsir Nurul Quran (Terjemah Karya Allamah Kamal Faqih Imani) Jakarta:Al-Huda

[3] HAMKA.1988. Tafsir Al-Azhar Juzu XVI, Jakarta:PT.Pustaka Panjimas

[4] Lajnah Pentashihan Mushaf Al-Quran.2014. Tafsir Al-Quran Tematik Jilid II,Jakarta: Lajnah Pentashihan Mushaf Al-Quran

[5] Lajnah Pentashihan Mushaf Al-Quran.2014.Tafsir Al-Quran Tematik II Terjemahan Karya Muhammad Nasib ar-Rifa'I,Jakarta:Lajnah Pentashihan Mushaf Al-Quran

[6] Syihabuddin,1999. Kemudahan dari Allah Ringkasan Tafsir Ibnu Katsir Jilid I,Jakarta: Gema Insani Press

[7] Syihabuddin,1999. Kemudahan dari Allah Ringkasan Tafsir Ibnu Katsir Jilid III Terjemahan Karya Muhammad Nasib ar-Rifa'I,Jakarta: Gema Insani Press

[8] Yusanto, Ismail.2011. Pengantar Ekonomi Islam,Bogor:Al-Azhar Pres

17 Lajnah Pentashihan Mushaf Al-Quran,Tafsir Al-Quran Tematik, (Jakarta:Lajnah Pentashihan Mushaf Al-Quran,2014),II,hlm 28 